\title{
Assessment of Dentists' Referral Patterns to Endodontist in Turkey
}

\author{
Öznur Sarıyılmaz ${ }^{1}$, Elif Kalyoncuoğlu ${ }^{2}$ \\ ${ }^{1}$ Ordu Oral and Dental Health Center, Ordu, Turkey \\ ${ }^{2}$ Department of Endodontics, Faculty of Dentistry, Ondokuz Mayis University, Samsun, Turkey; \\ Received: 25 March 2020, Accepted: 24 April 2020, Published online: 31 August 2020 \\ (C) Ordu University Institute of Health Sciences, Turkey, 2020
}

\begin{abstract}
Objective: To determine the factors of endodontic referral from general dental practitioners in Turkey.

Methods: A questionnaire containing 39 questions was designed to determine the need for referral to endodontists and the factors that influenced the decision to refer a patient to the endodontist. The survey was sent by e-mail to be registered dentists in a database of the Turkish Dental Association, and only unequivocal responses were included in calculating the percentage data. The categorical data were analyzed with a chisquare test, and the results were presented as frequency and percentage. The significance threshold for all tests was set at $\mathrm{p}<0.05$.

Results: The response rate was 5.5\% (655). The majority (96.8\%) of the respondents performed root canal treatment by themselves, and they refer the patient to an endodontist $(92.3 \%)$ when they encounter a challenging case. Statistical analyses revealed that female general dentists referred more patients to endodontists than males $(\mathrm{p}<0.05)$. "Limitations in mouth opening" was the most common referral reason in the patient related factors. "Difficult diagnosis" was the most common referral reason in the teeth and diagnosis-related factors. A statistically negative correlation was found between the professional experience and patient referral $(\mathrm{p}<0.05)$.

Conclusion: We concluded that many patient- and tooth-related factors influence the endodontic referral of patients. For a successful treatment, a general dentist should make a proper diagnosis and refer to a specialist if necessary.
\end{abstract}

Keywords: Case management, Endodontics, Referral, Questionnaires

Suggested Citation: Sariyilmaz O, Kalyoncuoglu E. Assessment of Dentists' Referral Patterns to Endodontist in Turkey. Middle Black Sea Journal of Health Science, 2020; 6(2):219-225

\section{Address for correspondence/reprints:}

Öznur Sarıyılmaz

Telephone number: +905052416390

ORCID-ID 0000-0003-4263-6851

E-mail: oznursariyilmaz@yahoo.com

DOI : $10.19127 / \mathrm{mbsjohs.709345}$

\section{Introduction}

There is a significant need for root canal treatment in the population. General dental practitioners (GDPs) have performed the vast majority of root canal treatments worldwide (deMoor et al, 2000; Kirkevang et al, 2000). Studies have shown that the success rate of root canal treatment in general dental practice is $60-85 \%$, and the success rate of root canal treatment by endodontist is $98 \%$ (Friedman et al., 2003; Alley et al., 2004). Studies have shown that teeth with inadequate root canal filling and coronal restoration were significantly more likely to have apical periodontitis (deMoor et al, 2000; Kirkevang et al., 2001). Previous studies reported that high 
retreatment requirements due to the recurrent apical periodontitis among Turkish population (Gencoglu et al., 2010; Ozbas et al., 2011; Kalender et al., 2013). To avoid this complication, the GDP should become more proficient at root canal treatment or refer the patient to an endodontist.

Referral of difficult cases to the endodontist who has advanced knowledge and skill is increases the success of root canal treatment (deMoor et al, 2000; de Cleen et al., 1993). The decision to refer to an endodontist is influenced by many patient- and dentist-related factors (Maupome and Sheiham, 2000; Elderton and Nuttal, 1983; Bader and Shugars, 1993) including clinical experience, confidence, training, working environment, etc (Bader and Shugars, 1993). However, there is little information about when and why dental practitioners refer to an endodontist. There are some published guidelines in endodontic practice which were prepared by specialists to help the practitioners determine the difficulty of a root canal treatment (Rosenberg and Goodis, 1992; Falcon et al., 2001; Ree et al., 2003). The first questionnaire was prepared at the University of California for selection undergraduate student patients in the endodontic department (Rosenberg and Goodis, 1992). Later, Falcon et al. submitted a different form to determine the difficulty of endodontic cases (Falcon et al., 2001). The latest form was published by the American Association of Endodontics (AAE) "endodontic case difficulty assessment form" and was created in 1999 with updates in 2006 (available at https://www.aae.org/uploadedfiles/dental_profession als/endodontic_case_assessment/2006casedifficultya ssessmentformb_edited2010.pdf). The aim of these guidelines is to make a standardized protocol that provides a systematic approach for patient evaluation and provide more objective decisions. The main advantage of this guides is to help the dental practitioners decide whether to treat or refer the patient (Messer, 1999).

To improve the quality of endodontic therapy performed by dentists, it is important to determine the need and reasons for referral to endodontists. There have been no previous studies on the factors that may influence the decision to refer a patient to endodontists in a Turkish population. The purpose of this study was to analyze the need for referral to an endodontist and to determine the factors influencing referral among Turkish dental practitioners.

\section{Methods}

The local university clinical research ethics committee approved the protocol of this study (Decision date: 15.04.2015, Decision no: 2015/125).
A questionnaire containing 39 questions was given to GDPs to identify the factors that influence the referral decision. A short explanation containing the purpose of the questionnaire was added. The name and other information concerning the identity of the participants were not requested.

The questionnaire was modified from the "endodontic case difficulty assessment form" created by AAE. A pilot study including 50 dentists was performed to understand whether the questions were easy to understand. Based on these responses, necessary revisions were performed in the questionnaire.

In the first part of the questionnaire, the demographic information of the participants including clinical experience and gender of GDP were evaluated. According to the clinical experience, the dentists were divided into four groups: group A (one years in practice), group B (2-10 years), group C (11-19 years), and group D (more than 20 years). In the second part of questionnaire, the "endodontic case difficulty assessment form" was applied and the endodontic referral needs were analyzed. Here, the question about patient-related factors, diagnostic and treatment considerations and additional considerations were asked, and the results were evaluated for each participant. The survey was sent by e-mail to the each dentist registered in the database of Turkish Dental Association. Blank or twice answered surveys were excluded from the study. Only unequivocal responses were included in calculating the percentages.

\section{Data analysis}

95\% confidence to participate in the survey, 655 people were selected $\pm 3.7 \%$ with acceptable error. The data were analyzed with the statistical software IBM SPSS V21 (Chicago, USA). Categorical data were analyzed with chi-square test, and the results were presented as a frequency and a percentage. The significance threshold for all tests was set at $p<0.05$. We used a binary comparison of categorical data held in Minitab Statistical Software 15 software package to compare to Fisher's Exact (Two Tailed) test.

\section{Results}

The response rate was 5.5\% (655). The ratio of female-to-male respondents was 298(45.5\%):356(54.4\%). Statistical studies showed that female GDPs referred (97.3\%) more patients to endodontist than males $(89.9 \%)(\mathrm{p}<0.05)$ (Table 1). 
Table 1. The effect of gender to patient referral

\begin{tabular}{ccc}
\hline Referral Rate & \% of total & p value \\
\hline Female & $97.3 \%$ & \multirow{2}{*}{0,0001} \\
Male & $89.9 \%$ & \\
\hline
\end{tabular}

The majority of the respondents $(37.7 \%)$ were group B dentists; $27.5 \%$ were group C, $26.1 \%$ were group $\mathrm{D}$, and the minority were group A $(8.5 \%)$. A statistically negative correlation was found between the professional experience and patient referral $(p<0.05)$. Responses from group A dentists were more likely than group D. Group B dentists more often referred patients to endodontist than Group D dentists (Table 2).

Table 2. Experience in the profession and patient referral

\begin{tabular}{ccc}
\hline Year of graduation & Referral rate & p value \\
\hline Group A & $100 \%(56)^{\mathrm{c}}$ & \\
Group B & $94.7 \%(234)^{\mathrm{e}}$ & 0.008 \\
Group C & $93.9 \%(169)$ & \\
Group D & $88.3 \%(151)$ & \\
\hline
\end{tabular}

In the column; a: Comparison between group $\mathrm{A}$ and Group $\mathrm{B}, \mathrm{b}$ : Comparison between group A and Group C, c:

Comparison between group A and Group D, d: Comparison between group B and Group C, e: Comparison between group B and Group D, f: Comparison between group C and Group D

$3.2 \%$ of dentists had never performed a root canal treatment. In any given week $57.4 \%$ of dentists treated between 1-10 root canals, and $32.5 \%$ of dentists treated between $10-25 ; 6.4 \%$ treated more than 25 . In terms of referral, $6.7 \%$ did this never, $69.5 \%$ rarely, $17.4 \%$ occasionally, $4.9 \%$ often, and $0.6 \%$ usually (Table 3 ).

Table 3. Frequency of referral

\begin{tabular}{cc}
\hline Frequency & \% of total \\
\hline Never & 6.7 \\
Rarely & 69.5 \\
Occasionally & 17.4 \\
Often & 4.9 \\
Usually & 0.6 \\
\hline
\end{tabular}

Situations in which the GDP refers are shown in Table 4. The most common patient-based reasons were significant limitations in mouth opening $(73.3 \%)$ and extreme gag reflex $(66.4 \%)$. The most common diagnostic and treatment considerations were difficult diagnosis $(60.6 \%)$ and non-visible canals on the radiograph $(55.4 \%)$. When additional considerations were evaluated, the most common referral reasons were alveolar fracture $(56.7 \%)$ and external resorption (54.8\%).

\section{Discussion}

The dentist's undergraduate and post-graduate education is one of the most important factors that affect the success of root canal treatment (deMoor et al, 2000). The decision to perform an endodontic treatment or refer to an endodontist depends on the GDP's evaluation of their knowledge and skills (Peciuliene et al., 2010). Previous studies have suggested various assessment forms to determine the difficulty of root canal treatment (Rosenberg and Goodis, 1992; Falcon et al., 2001; Ree et al., 2003). In this study an "endodontic case difficulty assessment form" was utilized because it is the most recent and comprehensive assessment form.

Questionnaire surveys can be applied by face-toface, telephone, mail and via the Internet. Questionnaires performed via the Internet are preferable because of ease, speed, and access (Schonlau et al., 2002). Thus, this survey was distributed in Turkey via the Internet. However, internet-based surveys have a low response rate. Information about the topic was added to the survey, and it was also sent to GDPs with a corporate extension to improve reliability as recommended by other studies (Avcioglu, 2014).

There are currently 11,749 dentists registered with the Turkish Dental Association. 655 questionnaires were received for a response rate of 5.5\%. According to Ree et al. (20) 5858 GDPs maintain their own practice in the Netherlands, and 283 GDP (5\%) participated in their survey. Our response rate was similar to Ree at al (2003).

Barnes et al. (2011) reported that $94 \%$ of GDPs referred patients to endodontists for challenging endodontic cases whereas Abott et al. (2011) and Wolcott and Terlap (2014) reported 46\% and 43\% referral rates, respectively, in serial endodontic referral rate studies. The referral rates of this study (92.3\%) were similar to the referral rates of Barnes et al. (21). Otherwise Abott et al. (2011) and Wolcott and Terlap (2014) reported lower referral rates than this study. In these studies, the authors showed that one-third of the GDPs performed root canal treatment even though they think that they should have referred to an endodontist.

The results of this study showed that female GDPs were likely to refer than males. This concurs with previous surveys (Zemanovich et al., 2006; Cottrell et al., 2007). According to Abott et al. (2011) the reason for the high referral rate of female GDPs is their preference for less risky treatment choices and more positive perception of the endodontist and their work versus male GDPs. Peciuliene et al. (2010) investigated the reasons for referral to a specialist for 
Table 4. Factors effect on decision to refer

\begin{tabular}{|c|c|c|}
\hline \multicolumn{2}{|c|}{ Factors influence referral behavior } & Referral rate $(\%)$ \\
\hline \multicolumn{3}{|c|}{$\begin{array}{l}\text { Patient Considerations } \\
\end{array}$} \\
\hline Medical history & Complex medical history & 63.7 \\
\hline Anesthesia & Difficulty achieving anesthesia & 28.5 \\
\hline Patient disposition & Uncooperative patient & 49.3 \\
\hline Ability to open mouth & Significant limitation mouth opening & 73.2 \\
\hline Gag reflex & Extreme gag reflex & 66.4 \\
\hline Emergency condition & Severe pain or swelling & 38.7 \\
\hline \multicolumn{3}{|c|}{ Diagnostic and treatment considerations } \\
\hline Diagnosis & $\begin{array}{c}\text { Difficult diagnosis } \\
\end{array}$ & 60.6 \\
\hline Radiographic difficulties & $\begin{array}{l}\text { Extreme difficulty obtaining/interpreting } \\
\text { radiographs }\end{array}$ & 54.3 \\
\hline \multirow[b]{2}{*}{ Position in the arch } & $2^{\text {nd }}$ and $3^{\text {rd }}$ molar & 25.4 \\
\hline & $\begin{array}{l}\text { Extreme inclination and extreme rotation } \\
\qquad(>30)\end{array}$ & 43.9 \\
\hline \multirow{2}{*}{ Morphologic aberrations of crown } & $\begin{array}{ll}\text { Fusion } \\
\end{array}$ & 43.6 \\
\hline & Dens in dente & 38.7 \\
\hline \multirow{6}{*}{ Canal and root morphology } & $\begin{array}{c}\text { Extreme curvature }\left(>30^{0}\right) \text { or S- shaped } \\
\text { curvature }\end{array}$ & 42.5 \\
\hline & Mandibular premolar or anterior with 2 roots & 6.4 \\
\hline & Maxillar premolar with 3 roots & 14.5 \\
\hline & Canal divides in the middle or apical third & 32.3 \\
\hline & Very long tooth $(>25 \mathrm{~mm})$ & 14.6 \\
\hline & Open apex & 40 \\
\hline $\begin{array}{c}\text { Radiographic appearance of root } \\
\text { canals }\end{array}$ & Canal(s) not visible & 55.4 \\
\hline \multicolumn{3}{|c|}{ Additional considerations } \\
\hline \multirow{3}{*}{ Resorption } & Extensive apical resorption & 30 \\
\hline & Internal resorption & 49.9 \\
\hline & External resorption & 54.8 \\
\hline \multirow{5}{*}{ Trauma history } & Complicated crown fracture of immature teeth & 34.8 \\
\hline & Horizontal root fracture & 55.2 \\
\hline & Alveolar fracture & 56.7 \\
\hline & Intrusive, extrusive, lateral luxation & 38.3 \\
\hline & Avulsion & 38.9 \\
\hline \multirow{3}{*}{ Endodontic treatment history } & Perforation & 26.4 \\
\hline & Ledge & 23 \\
\hline & Separated instrument & 38.7 \\
\hline \multirow{4}{*}{ Periodontal endodontic condition } & Concurrent severe periodontal disease & 28.3 \\
\hline & Cracked teeth with periodontal complications & 34.1 \\
\hline & Combined endodontic/periodontic lesion & 45.8 \\
\hline & Root amputation prior to endodontic treatment & 44.2 \\
\hline
\end{tabular}

endodontic therapy among GDPs. The results revealed that the referral rates of less experienced GDPs were higher than experienced GDPs. In contrast, Caplan et al. (1999) reported that GDPs with 10 years or more experience were more likely to refer. Ree et al. (2003) found no significant relationship between years of experience and referral rate. Here, a statically negative correlation was found between the professional experience and patient referral. This agrees with Peciuliene et al. (2010) and disagrees with Caplan et al. (1999) and Ree et al. (2003). The difference between these studies might be the 
educational differences and/or the number of endodontics specialists in these countries. The cost and insurance coverage of endodontic treatment in these countries might be also having effect on the difference between the studies.

Here, the factors that influenced referral were examined with three main categories: "patient considerations", "diagnostic and treatment consideration" and "additional considerations". Patient consideration consisted of medical history, anesthesia, patients' disposition, ability to open the mouth, gag reflex, and emergency conditions. The diagnosis, radiographic difficulties, position in the arc, morphologic aberrations of crown, canal and root morphology, and radiographic appearance of root canals were investigated under diagnostic and treatment considerations. Finally, resorption, trauma history, endodontic treatment history and periodontal/endodontic condition were investigated under additional considerations. A significant limitation in mouth opening (73.2\%) and extreme gag reflex $(66.4 \%)$ were the most effective factors influencing endodontic referral related to patient considerations. Difficult diagnosis (60.6\%) and nonvisible canals on the radiograph $(55.4 \%)$ had highest referral rates in terms of diagnostic and treatment consideration. Alveolar fracture $(56.7 \%)$ was most common reason for endodontic referral related to additional considerations. The "patient-related factors" were the most effective category of endodontic referral.

Several studies on endodontic referral have been published. Harty reported that most common reasons for endodontic referral were previous root fillings (19.8\%), inability to control pain or swelling (13.7\%) and diagnostic problems (12.8\%) (Harty, 1992). Management of pain (\%24), blocked canals (17\%) and endodontic retreatment $(\% 15)$ were the most common reasons of endodontic referral reported by Abbott in Australia (Abbott, 1994). Hommez et al. (2003) found that the most common reasons for endodontic referral were silver point retreatment $(56.7 \%)$ and perforation $(47.6 \%)$ in Belgium. Apicoectomy/retrofill (84-95\%) and external root resorption were the top reasons for endodontic referral in the Pacific Northwest (Caplan et al., 1999). Obstruction in canals (54\%) and the presence of post, crown, and bridge restoration of teeth (37\%) were common reasons for endodontic referral in Holland (Ree et al., 2003). Peciuliene et al. (2010) found that the persistent symptoms $(82.4 \%)$ and difficulty in diagnosis (74.2\%) were common reasons for endodontic referral in Lithuania. Persistent pain $(29.5 \%)$, gingival swelling and sinus tract $(24.1 \%)$ were the most common reasons in Korea (Kim, 2014). In this study the most referral reasons were significant limitations in mouth opening $(73.3 \%)$ and extreme gag reflex (66.4\%). Different reasons and proportions of endodontic referral are due to educational differences of dental faculties between different countries. The endodontist availability could also affect the results. One limitationof this study is the low response rate $(5.5 \%)$. However, low response rates are a common issue for Internet-based questionnaires (Avcioglu, 2014). Face-to-face surveys could solve this problem in further studies.

\section{Conclusion}

The major factors underlying endodontic referral were the complex medical history and significant limitations in mouth opening. Referral to an endodontist depends on many reasons like patients and tooth-related factors that were investigated here. The resources of the dental establishment for patients and financial issues including insurance coverage might also influence referral. Further studies regarding the relationship between referral behavior and dental establishments' opportunities as well as financial issues like insurance coverage should be performed. The GDP should confirm endodontic referral for challenging cases, and dental schools should give training about endodontic referral.

\section{Acknowledgements}

Summary of this study was presented as a poster presentation at 2015 European Society of Endodontology biennial congress, Barcelona, Spain

Ethics commitee approval: Ethics committee approval was received for this study from the Clinical Research Ethics Committee of Ondokuz May1s University (Decision date: 15.04.2015, Decision no: 2015/125).

Peer-review: Externally peer-reviewed.

Authorship Contributions: Conception: O.S., E.K., Design: O.S., E.K., Supervision: E.K. Fundings: O.S. Materials: O.S. Data Collection or Processing: O.S., Analysis or Interpretation: O.S., E.K., Literature Rewiev: O.S., Writing: O.S., Critical review: E.K.

Conflict of Interest: No conflict of interest was declared by the authors..

Financial Disclosure: The authors declared that this study has received no financial support. 


\section{References}

Abbott JA, Wolcott JF, Gordon G, Terlap HT Survey of general dentists to identify characteristics associated with increased referrals to endodontists. J Endod. 2011;37(9):1191-6.

Abbott PV. Analysis of a referral-based endodontic practice: Part 1. Demographic data and reasons for referral. J Endod. 1994;20(2):93-6.

Alley BS, Kitchens G, Alley L, Eleazer P. A comparison of survival of teeth following endodontic treatment performed by general dentists or by specialists. Oral Surg Oral Med Oral Pathol Oral Radiol Endod. 2004;98(1):115-8.

Avcioglu GŞ. Internet survey applications in social sciences: response rate, data quality, sample problems and solutions. International Journal of Human Sciences 2014;11:89-113.

Bader JD, Shugars DA. Agreement among dentists' decisions for restorative treatment. J Dent Res. 1993;72(5):891-6.

Barnes, S. Patel \& F. Mannocci. Why do general dental practitioners refer to a specific specialist endodontist in practice? Int Endod $J$. 2011;44(1):21-32.

Caplan DJ, Reams G, Weintraub JA (1999). Recommendations for Endodontic Referral among Practitioners in a Dental HMO. J Endod. 1999;25(5):369-75.

Cottrell DA, Reebye UN, Blyer SM. Referral patterns of general dental practitioners for oral surgical procedures. J Oral Maxillofac Surg. 2007;65(4):686-90.

de Cleen MJH, Schuurs AHB, Wesselink PR, Wu MK. Periapical status and prevalence of endodontic treatment in an adult Dutch population. Int Endod J. 1993;26(2):112-9.

deMoor RJG, Hommez GMG, De Boever JG, Delme KIM, Martens GEI. Periapical health related to the quality of root canal treatment in a Belgian population. Int Endod J. 2000;33(2):113-20.

Elderton RJ, Nuttal NM. Variation among dentists in planning treatment. Br Dent J. 1983;154(7):201-6.

Falcon HC, Richardson P, Shaw MJ, Bulman JS, Smith BGN. Developing an index of restorative treatment need. Br Dent J. 2001;190(9):479-86.

Friedman S, Abitbol S, Lawrence HP. Treatment outcomes in endodontics: The Toronto Study. Phase 1: Initial Treatment. $\mathbf{J}$ Endod. 2003;29(12):787-93.

Gencoğlu N, Pekiner FN, Gumru B, Helvacioğlu D. Periapical status and quality of root fillings and coronal restorations in an adult Turkish subpopulation. Eur J Dent. 2010;4(1):17-22.
Harty FJ. A survey of endodontic procedures performed by practitioners in limited practice. Int Endod J. 1992 Jan;25(1):25-8.

Hommez GM, De Moor RJ, Braem M. Endodontic treatment performed by Flemish dentists. Part 2. Canal filling and decision making for referrals and treatment of apical periodontitis. Int Endod $\mathrm{J}$. 2003;36(5):344-51.

Kalender A, Orhan K, Aksoy U, Basmaci F, Er F, Alankus. A Influence of the quality of endodontic treatment and coronal restorations on the prevalence of apical periodontitis in a Turkish Cypriot population. Med Princ Pract. 2013;22(2):173-7.

Kim S. Prevalence of referral reasons and clinical symptoms for endodontic referrals. Restor Dent Endod. 2014;39(3):210-4.

Kirkevang LL, Orstavik D, Ho Orsted-Bindslev P, Wenzel A. Frequency and distribution of endodontically treated teeth and periapical periodontitis in an urban Danish population. Int Endod J. 2001;34(3):198-205.

Kirkevang LL, Orstavik D, Ho Orsted-Bindslev P, Wenzel A. Periapical status and quality of root fillings and coronal restorations in a Danish population. Int Endod J. 2000;33(6):509-15.

Maupome G, Sheiham A. Clinical decision-making in restorative dentistry. Content-analysis of diagnostic thinking processes and concurrent concepts used in an educational environment. Eur J Dent Educ. 2000;4(4):143-52.

Messer HH. Clinical Judgement And Decision Making In Endodontics. Aust Endod J. 1999;25(3):124-32.

Ozbas H, Aşcı S, Aydın Y. Examination of the prevalence of periapical lesions and technical quality of endodontic treatment in a Turkish subpopulation. Oral Surg Oral Med Oral Pathol Oral Radiol Endod. 2011;112(1):136-42.

Peciuliene V, Rimkuviene J, Maneliene R, Drukteinis $S$. The need and reasons for referrals to specialists among Lithuanian general dentists. Medicina (Kaunas). 2010;46(9):611-5.

Ree MH, Timmerman MF, Wesselink PR. An evaluation of the usefulness of two endodontic case assessment forms by general dentists. Int Endod J. 2003;36(8):545-55.

Ree MH, Timmerman MF, Wesselink PR. Factors influencing referral for expert endodontic treatment among a group of Dutch general practitioners. Int Endod J 2003;36: 129-34.

Rosenberg RJ, Goodis HE. Endodontic case selection: to treat or to refer. J Am Dent Assoc. 1992;123(12):57-63. 
Schonlau M, Fricker, RD, Elliott MN. Conducting research surveys via e-mail and the web. Santa Monica: Rand; 2002.

Wolcott JF, Terlap HT. Follow-up Survey of General Dentists to Identify Characteristics Associated with Increased Referrals to Endodontists. J Endod. 2014;40(2):204-10.

Zemanovich MR, Russell EB, Abbott DM, Maynard GJ Jr, Lanning SK. Demographic variables affecting patient referrals from general practice dentists to periodontists. J Periodontol. 2006;77(3):341-9. 